\title{
TOXICITY AND REPELLENT ACTIVITY OF SPINOSAD AND ORANGE OIL AGAINST Rhizopertha dominica F. AND Tribolium castaneum (HERBST) \\ Abo-Arab, R.B ${ }^{1}$; S. S.Awadalla ${ }^{2}$; A. H. Abd El-Salam ${ }^{2}$ and El-Zahraa A. El-Maadawy ${ }^{1}$ \\ 1. Plant Protection Research Institute, Sakha, Kafr El-Sheikh, Egypt. \\ 2. Economic Entomology Department, Faculty of Agriculture, Mansoura Universiy, Egypt.
}

\begin{abstract}
The lesser grain borer, Rhizopertha dominica Fabricius and the red flour beetle, Tribolium castaneum Herbst, are of the most insect species which cause the highest grain damage. Many chemical insecticides related to different groups used as protectants to stored products presented serious problems to human health and environment. To avoid these disadvantages, laboratory experiments were carried out to evaluate two materials namely, plant oil (Orange oil) and bioinsecticide, spinosad as stored wheat grain protectants against $T$. castaneum and $R$. dominica using two bioassays technique, mixing with medium and repellency at different exposure periods (72 $\mathrm{h}$ for mixing with feeding medium and $24 \mathrm{~h}$ for repellency). Results obtained revealed that the two tested materials, orange oil and spinosad had moderately action on the two tested insects either by mixing with medium or by repellent bioassay methods. Data cleared that the effect of the tested materials increased with the increasing of concentration and period of exposure especially with mixing bioassay. For repellent effect, the highest level of concentration had the most action on both $T$. castaneum and $R$. dominica. Except orange oil against $T$. castaneum the effect of materials tested decreased through $24 \mathrm{~h}$ of exposure. Spinosad showed nearly similar effect on the two tested insects while $R$. dominica was found to be more tolerant than $T$. castaneum with orange oil. Finally, our findings suggest that spinosad and orange oil may to be potential protectants against $R$. dominica and $T$. castaneum in stored wheat grain principally with mixing bioassay technique.
\end{abstract}

\section{INTRODUCTION}

Major insect pests of stored wheat include Rhizopertha dominica Fabricious, Sitophilus oryzae L., Cryptolestes ferrugineus Stephens, Tribolium castaneum Herbst and Oryzaephilus surinamensis L. The first two species cause the most grain damage because the immature stages develop inside the grain kernel (Hagstrum and Subramanyam, 2006). Stored grain insect pests have been damaging our economy by infesting agricultural stored products. These are responsible for worldwide loss of $10-40 \%$ in the stored grain annually (Matthews, 1993). In such a situation, protection of stored grain and agricultural products against insect infestation is an urgent need, various synthetic insecticides have been used, but insects have acquired resistance against most of these synthetic pesticides. Also, these insecticides causes great hazards for environment and consumers due to residual property. Thus, it 
is an urgent need to develop new alternatives that must be ecologically sound with no residual activity and adverse effect on other non-target animals to control stored product insect pests. In this regard, many plant products have been evaluated for their toxic properties against different stored grain pests (Su, 1990; Mukherjee and Joseph, 2000) especially in form of essential oils (Shaaya et al., 1991;; Ngamo et al., 2007). Spinosad is a naturally occurring mixture of two active compounds spinosyn A and spinosyn D (salgado, 1998). As a part of future strategies for stored product insect control essential oils with repellent and/or insecticidal properties should be studied. therefore, the aim of the present work was to study the toxicity as well as repellent activity of orange oil and spinosad against the red flour beetle, $T$. castaneum and the lesser grainborer, Rhizopertha dominica.

\section{MATERIALS AND METHODS}

Insects:

Two important coleopteran stored grain pests were assessed in the current investigation, Lesser grain borer, $R$. dominica (F.) (Bostrychidae: Coleoptera) and red flour bettle, T. castaneum (Herbst) (Tenebrionidae: Coleoptera) . The original stock culture of the two insects were obtained from stored product pest laboratory, Plant Protection Research Institute, Sakha Agricultural Research Station. The insects were reared on wheat grain and wheat flour for $R$. dominica and $T$. castaneum, respectively in laboratory at $30 \pm 2^{\circ} \mathrm{C}$ and $75 \pm 5 \%$ R.H.

\section{Chemicals}

\section{Bioinsecticide}

Tracer:

Common name: Spinosad

Chemical name: Mixture of spinosyn A and spinosyn D

Spinosyn A:

(2R, 3as, 5bs, 9s, 13s, 14R, 16bR) -2-(6-deoxy-2,3,4-Tri-o-methyl-aL-Mannopyranosyloxy)-13-(4-dimethylam-ino2,3,4,6-tetradeoxy- $\beta$-D erythropyranosyloxy)-9-ethyl 2, 3, 3a, 5a, 5b, 6, 7, 9, 10, 11, 12, 13, 14, 15, 16a, 16b-hexadecahydro 14-methyl-1H-8-oxacyclododeca[b]as-indacene-7, 15-dione

\section{Spinosyn D:}

(2s, 3aR, 5as, 5bs, 9s, 13s, 14R, 16as, 16bR)-2-(6-deoxy-2, 3, 4-tri-o-methyl-a-LMannopyranosyloxy)-13-(4-dimethylamino-2, $3, \quad 4, \quad 6$ tetradeoxy- $\beta$-Derythropyranosylo-xy)-9-ethyl-2, 3, 3a, 5a, 5b, 6, 7, 9, 10, 11, 12, 13, 14, 15, 16a , 16b-hexadecahydro-4, 14-dimethyl-1H-8-oxacyclododeca[b]as-indacene-7, 15dione

The applied formulation: Tracer $24 \%$ SC .

Source: Nile valley for Agricultural Development, Giza, Egypt.

Plant oil

PREV- AM

Common name: Orange oil 
Source: Nile valley for Agricultural Development, Giza, Egypt.

Methods

Grain treatments (mixing with feeding medium):

Batches of whole grain were weighed $(10 \mathrm{gm})$ and placed in glass jars $(250 \mathrm{ml})$ for $R$. dominica or $20 \mathrm{~g}$ of cracked wheat grains for $T$. castaneum. The tested insecticide (Spinosad) was diluted in water and added to grains at rates which give the required concentration 10,50, 100 and 150 $\mathrm{ppm}$ ), while orange oil was diluted with acetone and added to the grains at rate which gave the required concentration $(40000,20000,10000,5000$ and $2500 \mathrm{ppm})$ for $T$. castaneum, $(1250,625,312.5$ and $156.25 \mathrm{ppm})$ for $R$. dominica, jars were shaken by hand and grains were allowed to dry at room temperature. Ten unsexed adults of both insects (1-2 weeks old) were introduced to jars containing treated grain, 3 replicates were set up for both treatment and control. Mortality counts were recorded daily and corrected by

Abbott's formula (1925).

Repellent activity :

A choice bioassay system was used to evaluate repellency of orange oil and spinosad. Half filter paper disks of $8 \mathrm{~cm}$ diameter were treated with $0.5 \mathrm{ml}$ acetonic solutions of the orange oil $(40000,20000,10000$ and $5000 \mathrm{ppm})$ and water solutions of spinosad (100, 50, 25 and $12.5 \mathrm{ppm})$. Solution of the spinosad was left to dry. Half of the bottom of a Petri dish was covered with the treated filter paper, while the other half was covered with a filter paper disk impregnated with $0.5 \mathrm{ml}$ acetone in orange case but with spinosad impregnated with $0.5 \mathrm{ml}$ water in spinosad. Ten unsexed adults were put into each Petri dish and the lid was sealed within place with parafilm. Three replicates were run for each tested concentration. So that 30 adults were assayed per concentration. The test was carried out in an incubator. The numbers of insects on the two half paper disks were recorded after 2, 3, 8, 16 and $24 \mathrm{~h}$ from the beginning of the test. Percentage of repellency (PR) was calculated as follows: $\mathrm{PR}=[\mathrm{C}-\mathrm{T}] /[\mathrm{C}+\mathrm{T}\} \times 100$ where $\mathrm{C}=$ number of insects on the untreated area $\quad T=$ treated

\section{RESULTS AND DISCUSSION}

Two bioassay methods, contact repellent activity were investigated in the present study on the two tested insects. T. castaneum and $R$. dominica to obtain the most suitable method and to compare between the two tested materials.

Toxicity of spinosad and orange oil :

To avoid the risk results in attacks of $T$. castaneum and $R$. dominica on wheat grains either quantity and quality effects, a laboratory experiments were carried out to study the potential activity of two materials one is a bioinsecticide, spinosad and the other is a plant oil, orange oil. The aim of this experiment was seeking safe alternatives replaced with hazardous chemical insecticides. Adults of $T$. castaneum and $R$. dominica were exposed to wheat and cracked wheat grain, respectively treated by different rates of the above toxicants wt/wt. Mortality counts were recorded after 24,48 and $72 \mathrm{hr}$. 
Data obtained in Table (1) summarized results in mixing with medium bioassay method of spinosad. Based on the $L_{50}$ values, mortality percentage increased with the increasing of concentrations and exposure periods for the two tested compounds with both the investigated insects.

Results in Table (2) showed that the effect of orange oil increased with the increasing of concentration and exposure period. Data cleared that, $R$. dominica was more susceptible than $T$. castaneum. Also, results obtained exhibited that spinosad was more toxic than orange oil against both $T$. castaneum and $R$. dominica (Table 1 and 2 ) .

Repellent effect of spinosad and orange oil :

According to results obtained in Tables (3,4,5 and 6), both the two tested materials had moderately deteriorate effect against the two tested insects, the highest rate of the tested materials had the most repellent effect on both $T$. castaneum or $R$. dominica where the percentage repellency at 100 ppm ranged from 74 to $34 \%, 60$ to $40 \%, 94$ to $100 \%$ and 86 to $66 \%$ with spinosad and orange oil against $T$. castaneum and $R$. dominica through the time of exposure $(24 \mathrm{~h})$, respectively. Except orange oil against $T$. castaneum the effect of materials tested decreased through the $24 \mathrm{~h}$ time of exposure. Also, results showed that the effect decreased with the decreasing of concentration and increasing time of exposure either with orange oil or spinosad against both $T$. castaneum or $R$. dominica. Spinosad showed nearly similar effect on the two tested insects while $R$. dominica was found to be more tolerant than $T$. castaneum with orange oil.

Studies in the United States of America on several species of insects show that among stored grain insecticides, spinosad is particularly effective against $R$. dominica (F.) (Fang et al., 2002 a,b; Toews and Subramanyam, 2003).

Although spinosad breaks down quickly in sunlight, limited published data suggest that spinosad in stored grain will be stable and loss of efficacy will be negligible (Fang et al., 2002 a).

Subsequently, spinosad may be exploited for insect control of stored product insects and is likely to be a safe alternative of chemical insecticides. The search of anti-insect chemicals naturally occurring in plants has received special attention in recent years. The biorational insecticides, those based on natural products and synthesized analogues of naturally occurring biochemicals, are more acceptable than other conventional chemical pesticides; because of assumed reputation for being environmentally innocuous, available and less hazardous to humans and non-target organisms (Me Closky et al., 1993 and Prakash and Rao, 1997).

There is now overwhelming evidence that many plant species exert divers biological effects on insects, i.e., killing, attracting, repelling, feeding deterring, growth inhibiting and sterilizing effects (Lichtenstein and Cosida 1963; Abbassy, 1969, 1974, 1981 and 1982; Ogendo et al., 2008; Derbalah and Ahmed, 2011 and Abdelgaleil et al., 2012).

Our findings are consistent with those reported in literature for stored product insect pests tested with different insecticides (Mishra et al., 2011). 
J. Plant Prot. and Path., Mansoura Univ., Vol.5 (1), January, 2014 
Table (3): Repellency of spinosad to $T$. castaneum through $24 \mathrm{hrs}$ of exposure time.

\begin{tabular}{|c|c|c|c|c|}
\hline \multirow{2}{*}{$\%$ PR (h) } & \multicolumn{4}{|c|}{ Concentration (ppm) } \\
\cline { 2 - 5 } & $\mathbf{1 0 0}$ & $\mathbf{5 0}$ & $\mathbf{2 5}$ & $\mathbf{1 2 . 5}$ \\
\hline 2 & $74 \%$ & $46 \%$ & $34 \%$ & $20 \%$ \\
\hline 4 & $66 \%$ & .0 & $26 \%$ & $6 \%$ \\
\hline 8 & $66 \%$ & $26 \%$ & $20 \%$ & $14 \%$ \\
\hline 16 & $54 \%$ & $34 \%$ & $26 \%$ & $6 \%$ \\
\hline 24 & $34 \%$ & $26 \%$ & $26 \%$ & $0 \%$ \\
\hline
\end{tabular}

Table (4): Repellency of spinosad to $R$. dominica through $24 \mathrm{hrs}$ of exposure time.

\begin{tabular}{|c|c|c|c|c|}
\hline \multirow{2}{*}{$\%$ PR (h) } & \multicolumn{4}{|c|}{ Concentration (ppm) } \\
\cline { 2 - 5 } & $\mathbf{1 0 0}$ & $\mathbf{5 0}$ & $\mathbf{2 5}$ & $\mathbf{1 2 . 5}$ \\
\hline 2 & $60 \%$ & $46 \%$ & $34 \%$ & $26 \%$ \\
\hline 4 & $34 \%$ & $34 \%$ & $26 \%$ & $20 \%$ \\
\hline 8 & $74 \%$ & $34 \%$ & $6 \%$ & $6 \%$ \\
\hline 16 & $74 \%$ & $46 \%$ & $26 \%$ & $0 \%$ \\
\hline 24 & $40 \%$ & $40 \%$ & $34 \%$ & $0 \%$ \\
\hline
\end{tabular}

Table (5): Repellency of orange oil to $T$. castaneum through $24 \mathrm{hrs}$ of exposure time.

\begin{tabular}{|c|c|c|c|c|}
\hline \multirow{2}{*}{$\%$ PR (h) } & \multicolumn{4}{|c|}{ Concentration (ppm) } \\
\cline { 2 - 5 } & $\mathbf{1 0 0}$ & $\mathbf{5 0}$ & $\mathbf{2 5}$ & $\mathbf{1 2 . 5}$ \\
\hline 2 & $94 \%$ & $74 \%$ & $43 \%$ & $40 \%$ \\
\hline 4 & $86 \%$ & $46 \%$ & $34 \%$ & $40 \%$ \\
\hline 8 & $80 \%$ & $74 \%$ & $46 \%$ & $40 \%$ \\
\hline 16 & $80 \%$ & $60 \%$ & $40 \%$ & $34 \%$ \\
\hline 24 & $100 \%$ & $77 \%$ & $34 \%$ & $34 \%$ \\
\hline
\end{tabular}

Table (6): Repellency of orange oil to $R$. dominica through $24 \mathrm{hrs}$ of exposure time.

\begin{tabular}{|c|c|c|c|c|}
\hline \multirow{2}{*}{$\%$ PR (h) } & \multicolumn{4}{|c|}{ Concentration (ppm) } \\
\cline { 2 - 5 } & $\mathbf{1 0 0}$ & $\mathbf{5 0}$ & $\mathbf{2 5}$ & \\
\hline 2 & $86 \%$ & $80 \%$ & $40 \%$ & $46 \%$ \\
\hline 4 & $66 \%$ & $66 \%$ & $40 \%$ & $66 \%$ \\
\hline 8 & $46 \%$ & $66 \%$ & $40 \%$ & $66 \%$ \\
\hline 16 & $60 \%$ & $60 \%$ & $40 \%$ & $60 \%$ \\
\hline 24 & $66 \%$ & $26 \%$ & $26 \%$ & $34 \%$ \\
\hline
\end{tabular}

Toxicity of the tested materials varied dependence on insect species and bioassay method. This variation may be connected the alimentary habit of insect species, morphology and genetic agents. Also, the type of the tested material plays an important role for affecting on the tested insects, where the 
chemical elements of each differ from compound to another. In addition to another factors such as the vapor pressure, molecular weight of each compound, which influence the level of toxicity.

The results clearly indicated that higher concentrations of the investigated materials for short periods were more effective than lower concentrations for longer periods. Insecticidal activity in the tested materials was related to their chemical composition, activity decreasing with the time because of component volatility. The differences between chemical composition of tested materials could be explain the variations observed in the insecticidal activities of these materials.

Beeman and Speirs (1986) found that avermectin ${ }_{\mathrm{B} 1}$ (abamectin) was extremely effective against 6 beetles and 3 moth pests of stored products. At dose $320 \mathrm{ppb}$ in wheat, all adults of 3 species of Coleoptera were killed in 3 weeks. For most of the coleoptera and Lepidoptera $96-100 \%$ suppression of progeny was achieved at doses of 10-160 ppb.

Abo-Arab and El-Hamady (1998) carried out studies to evaluate the efficiency of ivermectin as a protectant against three important stored-grain insects, namely, the rust red flour beetle, $T$. castaneum (Herbst), the rice weevil, S. oryzae L. and the cowpea weevil, Callosobruchus maculates F. using the technique of exposure to feeding medium, ivermectin exhibited considerable toxicity nearly equal to that of malathion. C. maculates showed the highest susceptibility to ivermectin followed by $S$. oryzae and $T$. castaneum, respectively. The compound also showed potential toxicity to the immature stage inducing reduction in the progeny. Thus, number of offspring and number of eggs (laid by C. maculatus) or their hatchability were greatly reduced.

The repellent effect of Ocimum gratissimum L. was evaluated against adults of $S$. oryzae (L.), T. castaneum (Herbst), Oryzaephilus surinamensis (L.), R. dominica (F.) and Collasobruchus chinensis (L.). The repellence of the oil in acetone was evaluated in choice bioassay at five rates $(0,1,2,3$ and $4 \mu \mathrm{l} / 2 \mathrm{~g}$ grain). Results showed that repellence of the oil was significantly influenced by concentration and time after treatment. $T$. castaneum was more tolerant than the other tested insects. All tested insects had percentage repellence (PR) values which ranged from $37.5 \%$ to $100 \%$. $O$. gratissimum oil is potential alternative to synthetic fumigants in the treatment of durable agricultural products (Ogendo et al., 2008).

Essential oils from plants are valuable secondary metabolites which have already bean used as raw materials in many fields, including performs, cosmetics, phytotherapy and nutrition. These oils also offer potential as sources of insecticides with environmental compatibility (Katz et al., 2008). Recently, many studies have focused on the possibility of using plant essential oils for application to stored grain to control insect pests (Collins, 2006; De Garvalho and De Fonseca, 2006).

The extracts and secondary metabolites of plants are among the most promising alternatives. These botanical pesticides have the advantage of providing novel modes of action against insects that can reduce the risk of 
cross-resistance as well as offering new leads for the design of target-specific molecules (Isman, 2006). Essential oils and their major constituents, mainly monoterpenoids, attracted research attention in recent years as potential alternatives to synthetic insecticides (Aslan et al., 2004).

Our findings suggest spinosad may to be a potential protectant against $R$. dominica and $T$. castaneum in stored grain. This potential use would be in combination with another protectant capable of controlling other members of the pest complex.

\section{REFERENCES}

Abbassy, M.A. (1969). Insecticidal activity of alkaloids isolated from certain plants. M.Sc. Thesis, Faculty of Agriculture, Alex. Univ., pp. 108 .

Abbassy, M.A. (1974). Toxicity of some plant constituents to insects. Ph.D. Thesis, Faculty of Agriculture, Alex. Univ., pp. 132.

Abbassy, M.A. (1981). Insecticidal and Synergistic volatile oils isolated from certain food and medicinal plants. Proc. $4^{\text {th }}$ Arab Pesticides Conf. Tanta Univ., IIIA, 409-414.

Abbassy, M.A. (1982). Naturally occurring chemicals for pest control. III. Insecticidal and synergistic alkaloid isolated from Schinus terbinthifolius Reddi Med., Fac. Land Bouww, Rijks Univ. Gent. 4712: 617-626.

Abbott, W.S. (1925). A method of computing the effectiveness of an insecticide. J. Econ. Ent. 18: $265-267$.

Abdelgaleil, S.A.M.; Badawy, M.E.I. and Shawir, M.S. (2012). Chemical composition and fumigant toxicity of essential oils isolated from Egyptian plants against stored product insects Sitophilus oryzae (L.) and Tribolium castaneum (Herbst). proc. 9 ${ }^{\text {th }}$. Int. Conf. on Controlled Atmosphere and Fumigation in Stored Product, Anatolia, Turkey, Arber Professional Congress Services, pp. 50-57.

Abo-Arab, R.B..S. and Sh.E.E. El-Hamady (1998). Ivermectin as a protectant against stored grain insects. Alex. Sci. Exch., 19: 419-427.

Aslan, I; Ozbek, H.; Calmasur, O. and Sahin, F. (2004). Toxicity of essential oil vapour to two greenhouse pests. Tetranychus urticae Koch and Bemisia tabaci Genn. Indust. J. of Crops Prod. 19: 169-173.

Beeman, R. W. and W. E. Speirs (1986). Toxicity, persistence and antagonism of avermectin B1 against stored-product insects. Proceedings of the Third International Working Conference on StoredProduct Entomology. October 23-28, 1983, Kansas State University, Manhattan, Kansas USA.

Collins, D.A. (2006). A review of alternatives to organophosphorus compounds for the control of storage mites. J. of Stored Prod. Res., 42: 395-426.

De Carvalho, C.C.R. and Da Fonseca, M.M.R. (2006). Carvone: why and how should one bother to produce this terpene. J. of Food Chem., 95: 413-422. 
Derbalah, A.S. and Ahmed, S.I. (2011). Oil and powder of spearmint as alternative to Sitophilus oryzae chemical control of wheat grains. J. of Plant Prot. Res., 51(2): 145-150.

Fang, L.; Bhadraraju, S. and Sean, D. (2002b). Persistence and efficacy of spinosad residue in farm stored wheat. J. Econ. Entomol., 95(5): 11021109.

Fang, L.; Suybramanyam, B.H. and Arthur, F.H. (2002a). Effectiveness of spinosad on four classes of wheat against give stored-product insects. J. Econ. Entomol., 95: 640-650.

Hagstrum, D.W. and Subramanyam, B. (2006). Fundamentals of StoredProduct Entomology. American Association of Cereal Chemists, St. Paul, Minnesota.

Isman, M. B. (2006). Botanical insecticides, deterrents, and repellents in modern agriculture and an increasingly regulated world. J. Annu. Review of Entomol., 51: 45-66.

Katz, T.M.; Miller, J.H. and Hebert, A. (2008). Insect repellents; historical perspectives and new developments. J. of American Academy Dermatology, 58: 865-871.

Lichtenstein, E.P. and Casida, J.E. (1963). Naturally occurring insecticides myristicin, an insecticide and synergist occurring naturally in the edible parts of parsnips. J. Agric. Food Chem., 11: 410-415.

Matthews, G.A. (1993). Insecticide application in the stored. In Matthews, G.A. and Hislop, E.C. (eds). Application Technology for Crop Protection, CAB, London, pp. 305-315.

Me Closky, C.; Arnason, G.C.; Donskov, N. ; Chenier, R.; Kaminski, G. and Philogenn, B.G.R. (1993). Third tropical level effect of Azadirachtin. J. Cannd. Entomol., 125: 163-165.

Mishra, B.B.; Tripathi, S.P. and Tripathi, C.P. (2011). Contact toxicity of essential oil of Citrus reticulate fruits peels against stored grain pests Sitphilus oryzae and Tribolium castaneum. J. Zoology, 6(3): 307-311.

Mukherjee, S.N. and Joseph, M. (2000). Medicinal plant extracts influencing insect growth and reproduction. J. Med. Arom. Plant Sci., 22: p. 38.

Ngamo, T.L.S.; Goudoum, A.; Ngassoum, M.B.; Mapongmetsen, Lognay, G.; Malaiise, F.; hance, T. (2007). Chronic toxicity of essential oils of 3 local aromatic plants towards Sitophilus zeamais Motsch (Coleoptera: Curculionidae). Afr. J. Agric. Res., 2: 164-167.

Ogendo, J.O. ; Kostyukovsky, M. ; Ravid, U. ; Matasyoh, J.C. ; Deng, A.L.; Omolo, E.O. ; Kariuki, S.T. and Shaaya, E. (2008). Bioactivity of Ocimum gratissimum $\mathrm{L}$. oil and two of its constituents against five insect pests attacking stored food products. J. of Stored Prod. Res. 44 (4): 328-334.

Prakash, A. and J. Rao (1997). Botanical pesticides in agriculture. A review of the literature Lewis Publishing Co., London, pp. 461.

Salgado, V. L. (1998). Studies on the mode of action of spinosad insect symptoms and physiological correlates. Pesticide Biochemistry and Physiology 60: 91-102. 
Shaaya, E.; Ravid, Y.; Paster, N.; Juven, B.; Zisman, Y. and Pistarev,V. (1991). Fumigant toxicity of essential oils against four major stored product insects. J. Chem. Ecol., 17: 499-504.

Su, H.F.C. (1990). Biological activities of hexane extract of Piper cubeba against rice weevil and cowpea weevils (Coleoptera: Curculionidae). J. Entomol. Sci., 25: 16-20.

Toews, M.D. and Subramanyam, B. (2003). Contribution of contact toxicity and wheat condition to mortality of stored product insect exposed to spinosad. J. of Pest Manag. Sci., 59(5): 538-544.

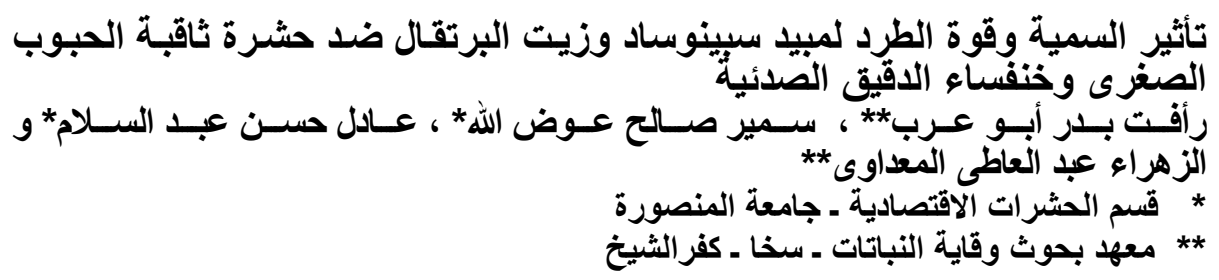

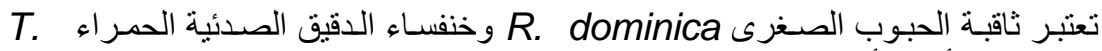

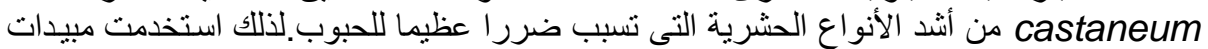

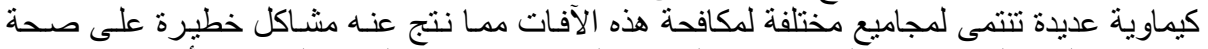

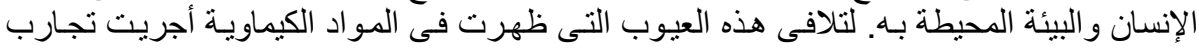

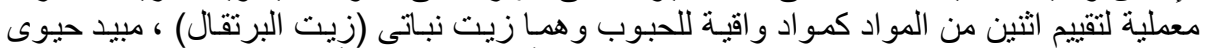

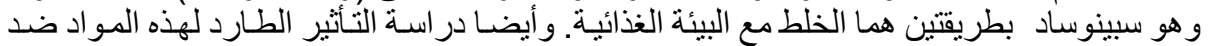

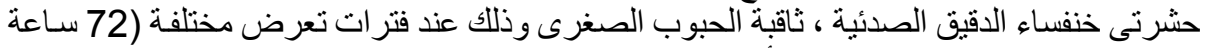

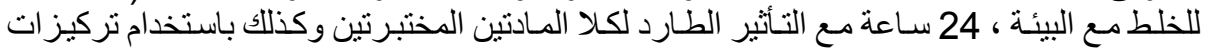

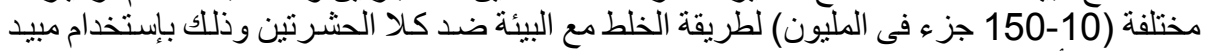

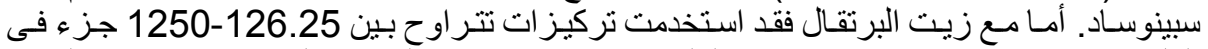

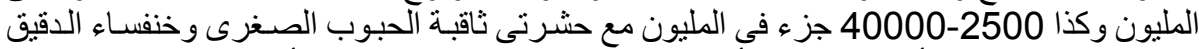

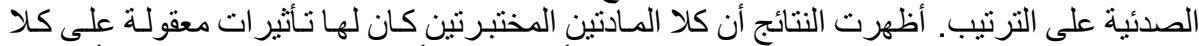

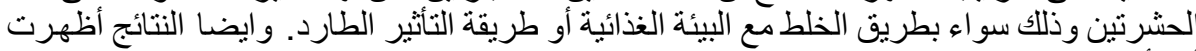

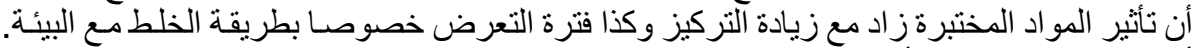

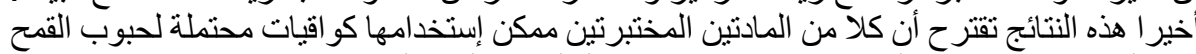
ضد الحشر تين موضوع الدر اسة خصوصنا بطريقة الخلط مع البيئة الغذائية.

كلية الزراعة - جامعة المنصورة مركز البحوث الزراعية
قام بتحكيم البحث

أ.دا على على عبد الهادى البدى أ.د/ احمد السيد عبد المجيد عليد 
J. Plant Prot. and Path., Mansoura Univ., Vol.5 (1): 23-32, 2014

Table (1): Toxicity of spinosad using mixing with feeding medium against $T$. castaneum and $R$. dominica at different periods.

\begin{tabular}{|c|c|c|c|c|c|c|c|c|c|c|c|c|c|c|c|c|}
\hline \multirow{3}{*}{ Treatment } & \multirow{3}{*}{$\begin{array}{c}\text { Conc. } \\
\text { ppm }\end{array}$} & \multirow{2}{*}{\multicolumn{3}{|c|}{ \%mortality }} & \multirow{2}{*}{\multicolumn{3}{|c|}{$\mathrm{LC}_{50}$}} & \multirow{2}{*}{\multicolumn{3}{|c|}{ Slope value }} & \multicolumn{6}{|c|}{ Confidence limits } \\
\hline & & & & & & & & & & & \multicolumn{2}{|c|}{$24 \mathrm{~h}$} & \multicolumn{2}{|c|}{$48 \mathrm{~h}$} & \multicolumn{2}{|c|}{$72 \mathrm{~h}$} \\
\hline & & $24 \mathrm{~h}$ & $48 \mathrm{~h}$ & $72 \mathrm{~h}$ & $24 \mathrm{~h}$ & $48 \mathrm{~h}$ & $72 \mathrm{~h}$ & $24 \mathrm{~h}$ & $48 \mathrm{~h}$ & $72 \mathrm{~h}$ & Lower & Upper & Lower & Upper & Lower & Upper \\
\hline \multirow{4}{*}{$\begin{array}{c}T . \\
\text { castaneum }\end{array}$} & 10 & 7 & 10 & 33 & \multirow{4}{*}{604.594} & \multirow{4}{*}{173.717} & \multirow{4}{*}{33.131} & \multirow{4}{*}{$0.924 \mid$} & \multirow{4}{*}{$1.217 \mid$} & \multirow{4}{*}{1.010} & \multirow{4}{*}{296.214} & \multirow{4}{*}{324.405} & \multirow{4}{*}{108.1} & \multirow{4}{*}{278.3} & \multirow{4}{*}{22.758} & \multirow{4}{*}{44.536} \\
\hline & 50 & 10 & 17 & 50 & & & & & & & & & & & & \\
\hline & 150 & $\begin{array}{l}23 \\
33\end{array}$ & $\begin{array}{l}33 \\
57\end{array}$ & $\begin{array}{l}67 \\
80\end{array}$ & & & & & & & & & & & & \\
\hline & 0 & 0 & 0 & 0 & & & & & & & & & & & & \\
\hline \multirow{5}{*}{$\begin{array}{c}R . \\
\text { dominica }\end{array}$} & 10 & 17 & 30 & 60 & \multirow{5}{*}{100.205} & \multirow{5}{*}{35.798} & \multirow{5}{*}{7.225} & \multirow{5}{*}{1.023} & \multirow{5}{*}{1.089} & \multirow{5}{*}{0.958} & \multirow{5}{*}{74.461} & \multirow{5}{*}{149.521} & \multirow{5}{*}{25.655} & \multirow{5}{*}{47.092} & \multirow{5}{*}{3.94} & \multirow{5}{*}{13.20} \\
\hline & 50 & 33 & 50 & 67 & & & & & & & & & & & & \\
\hline & 100 & 50 & 67 & 90 & & & & & & & & & & & & \\
\hline & 150 & 60 & 80 & 93 & & & & & & & & & & & & \\
\hline & 0 & 0 & 0 & 0 & & & & & & & & & & & & \\
\hline
\end{tabular}

Table (2):Toxicity of orange oil using mixing with feeding medium against $T$. castaneum and $R$. dominica at different induction

\begin{tabular}{|c|c|c|c|c|c|c|c|c|c|c|c|c|c|c|c|c|}
\hline \multirow{3}{*}{ Treatment } & \multirow{3}{*}{$\begin{array}{l}\text { Conc. } \\
\text { ppm }\end{array}$} & \multirow{2}{*}{\multicolumn{3}{|c|}{$\%$ mortality }} & \multirow{2}{*}{\multicolumn{3}{|c|}{$\mathrm{LC}_{50}$}} & \multirow{2}{*}{\multicolumn{3}{|c|}{ Slope value }} & \multicolumn{6}{|c|}{ Confidence limits } \\
\hline & & & & & & & & & & & \multicolumn{2}{|c|}{$24 \mathrm{~h}$} & \multicolumn{2}{|c|}{$48 \mathrm{~h}$} & \multicolumn{2}{|c|}{$72 \mathrm{~h}$} \\
\hline & & $24 \mathrm{~h}$ & $48 h$ & $72 \mathrm{~h}$ & $24 \mathrm{~h}$ & $48 \mathrm{~h}$ & $72 \mathrm{~h}$ & $24 \mathrm{~h}$ & $48 \mathrm{~h}$ & $72 \mathrm{r}$ & Lower & Upper & Lower & Upper & Lower & Upper \\
\hline \multirow[t]{4}{*}{$\begin{array}{c}T . \\
\text { castaneum }\end{array}$} & $\begin{array}{l}40000 \\
20000\end{array}$ & $\begin{array}{c}13.3 \\
6.7\end{array}$ & $\begin{array}{l}33.3 \\
23.3\end{array}$ & $\begin{array}{l}47.0 \\
33.3\end{array}$ & \multirow{4}{*}{290680} & \multirow{4}{*}{80241.8} & \multirow{4}{*}{42423.4} & \multirow{4}{*}{1.292} & \multirow{4}{*}{1.225} & \multirow{4}{*}{1.416} & \multirow{4}{*}{110770} & \multirow{4}{*}{6687100} & \multirow{4}{*}{50151} & \multirow{4}{*}{128623} & \multirow{4}{*}{31845.4} & \multirow{4}{*}{64645.2} \\
\hline & $\begin{array}{c}10000 \\
5000\end{array}$ & $\begin{array}{l}3.3 \\
0.0\end{array}$ & $\begin{array}{c}20.0 \\
3.3\end{array}$ & $\begin{array}{l}20.0 \\
10.0\end{array}$ & & & & & & & & & & & & \\
\hline & 2500 & 0.0 & 0.0 & 3.3 & & & & & & & & & & & & \\
\hline & 0 & 0.0 & 0.0 & 0.0 & & & & & & & & & & & & \\
\hline \multirow{5}{*}{$\begin{array}{c}R . \\
\text { dominica }\end{array}$} & 1250 & 29 & 44.4 & 70.3 & \multirow{5}{*}{3052.5} & \multirow{5}{*}{1746.8} & \multirow{5}{*}{559.7} & \multirow{5}{*}{1.398} & \multirow{5}{*}{1.758} & \multirow{5}{*}{1.257} & \multirow{5}{*}{1861.01} & \multirow{5}{*}{8384.2} & \multirow{5}{*}{1298.2} & \multirow{5}{*}{2850.9} & \multirow{5}{*}{113.2} & \multirow{5}{*}{737.7} \\
\hline & 625 & 18 & 15.0 & 48.1 & & & & & & & & & & & & \\
\hline & 312.5 & 7.1 & 11.1 & 37.0 & & & & & & & & & & & & \\
\hline & 156.25 & 3.5 & 3.7 & 26.0 & & & & & & & & & & & & \\
\hline & 0 & 6.7 & 10.0 & 10.0 & & & & & & & & & & & & \\
\hline
\end{tabular}


J. Plant Prot. and Path., Mansoura Univ., Vol.5 (1): 23-32, 2014 